\title{
ARTÍCULOS
}

\section{Expresión molecular del gen $N H X 1$ en respuesta al estrés hídrico y salino en plantas jóvenes de Eucalyptus grandis}

\author{
Molecular expression of the $N H X 1$ gene in response to hydric \\ and saline stress in young plants of Eucalyptus grandis
}

\author{
Ximena García ${ }^{a}$, María Cecilia Gamboa a , Erwin Krauskopf a,b* \\ ${ }^{a}$ Universidad Andrés Bello, Facultad Ciencias de la Vida, Centro de Biotecnología Vegetal, Santiago, Chile.

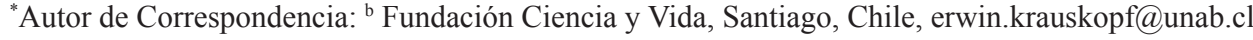

\begin{abstract}
SUMMARY
Plants are exposed to several types of abiotic stress that affect their development. Among these, salinity and drought affect large areas of land worldwide. Chile does not escape this reality, estimating that $49.1 \%$ of the territory have these characteristics. Due to the boom of forestry in Chile, the development of strategies aimed at using these low-quality soils becomes imperative. In this context, understanding the mechanisms involved in salt and drought stress in tree species such as Eucalyptus grandis has become essential. Thus, the permeability of the cell membrane was established by electrolyte leakage, recognizing that the plants exhibit damage after 12 hours of salt stress and after 10 hours of drought stress. Furthermore, the expression of a specific gene (NHXI) was determined on Eucalyptus grandis plants subjected to salt and water stress, establishing a rise in its expression in foliar and root tissue. From a physiological perspective, the observed response to abiotic stress is similar to that described for other plant species that have a shorter life cycle. Additionally, the increased expression of a specific gene (NHX1) under conditions of abiotic stress confirms it as a potential candidate for genetic improvement programs in woody species for the selection of individuals tolerant to these types of stress.
\end{abstract}

Key words: abiotic stress, $N H X 1$, gene expression, membrane permeability.

\section{RESUMEN}

Las plantas se encuentran expuestas a diferentes condiciones de estrés abiótico que perjudican su desarrollo. Entre estos destacan la salinidad y la sequía, dado que afectan grandes extensiones de terrenos alrededor del mundo. Chile no escapa a esta realidad, estimándose que el 49,1\% del territorio posee estas características. Con el auge de la industria forestal del país, se torna necesario desarrollar estrategias para aprovechar suelos de menor calidad. En este sentido, es fundamental la compresión de los mecanismos que participan en la tolerancia a salinidad y sequía en especies forestales como Eucalyptus grandis. Con este propósito se determinó la permeabilidad de la membrana celular a través de ensayos de fuga electrolítica, estableciéndose que las plantas exhiben daño después de 12 horas de exposición a estrés salino y después de 10 horas de exposición a estrés osmótico. Asimismo, se cuantificó la expresión génica de un gen especifico $(N H X 1)$ bajo condiciones de estrés salino e hídrico en plantas jóvenes de E. grandis, registrándose un incremento de su expresión tanto en tejido radicular como en tejido foliar. Desde una perspectiva fisiológica, la respuesta a estrés abiótico observada es similar a la descrita para otras especies vegetales que poseen un ciclo de vida más corto. Adicionalmente, el aumento de la expresión del gen $N H X 1$ bajo condiciones de estrés abiótico lo confirma como un potencial candidato para programas de mejoramiento genético para seleccionar especies leñosas tolerantes a estos tipos de estrés.

Palabras clave: estrés abiótico, $N H X 1$, expresión génica, permeabilidad de membrana.

\section{INTRODUCCIÓN}

Las plantas están expuestas durante el transcurso de su vida a diferentes condiciones de estrés abiótico lo que influye, junto a otros factores, su desarrollo. A modo de ejemplo, la salinidad afecta al $20 \%$ del área cultivable a nivel mundial (Jamil et al. 2011), estimándose que a mediados del siglo XXI se perderá aproximadamente el $50 \%$ de las tierras que actualmente son de uso agrícola y forestal (Jamil et al. 2011). Por otro lado, el estrés abiótico provocado por periodos de sequía prolongados genera una disminución del potencial hídrico de la tierra, lo que consecuentemente incrementa la concentración de sales en el suelo. Chile no escapa a esta realidad estimándose que el $49,1 \%$ de su territorio está afectado por estas características (Wesphal et al. 2015). Este fenómeno está presente en el 
país en las zonas áridas y semiáridas, es decir, desde la frontera chileno-peruana hasta la ciudad de Santiago (Torres y Acevedo 2008, Casanova 2013). Adicionalmente, el cambio climático está produciendo ciclos climáticos cada vez más impredecibles. Un estudio publicado por Fuenzalida et al. (2006) señalo que las proyecciones del cambio climático en la zona centro-sur de Chile generarían un déficit de lluvias que alcanzaría un $40 \%$, además de un incremento en la temperatura de $4{ }^{\circ} \mathrm{C}$ hacia el final este siglo. Como consecuencia, estas regiones presentan un alto grado de desertificación que podría moderarse mediante la introducción de especies vegetales tolerantes a la salinidad y la sequía.

Por otra parte, el auge en las exportaciones de productos madereros en Chile ha propiciado un incremento en la cantidad de plantaciones forestales, lo cual ha provocado una escasez de suelos para la expansión de estos bosques, ya que los terrenos forestales en la zona centro sur están utilizados a su máxima capacidad, concentrándose en estas regiones el $77 \%$ de las plantaciones forestales del país (INFOR 2016).

Una alternativa que surge frente a la problemática generada por la falta de suelos para plantaciones forestales consiste en el uso de terrenos del norte del país, que sin embargo presentan sequías recurrentes y alta salinidad de sus suelos. Por lo tanto, la comprensión de los mecanismos que subyacen a la tolerancia a salinidad en especies forestales se torna fundamental para enfrentar esta situación.

Para comprender los mecanismos que participan en la tolerancia a salinidad y sequía en especies del género $E u$ calyptus, se emplea como planta modelo Eucalyptus grandis Hill ex Maiden. Esta especie se encuentra totalmente secuenciada, por lo que su genoma está disponible según Goodstein et al. (2012). Además, E. grandis presenta solo un 1,5\% de divergencia génica con Eucalyptus globulus Labill. (Lu et al. 2008), la especie del género Eucalyptus más plantada en Chile (INFOR 2016).

El estrés abiótico causado por sequía y salinidad es el más severo que una planta puede enfrentar, al desencadenar una disminución en la capacidad de absorción de nutrientes, reduciendo las actividades metabólicas y la expansión celular. Esto genera una disminución en el crecimiento del organismo causando mermas considerables en la productividad de los suelos y pérdidas millonarias a las industrias. La alta concentración de sales en el suelo inhibe el crecimiento de la planta debido a la reducción en su capacidad para captar agua, efecto conocido como estrés osmótico. Asimismo, el ingreso de altas concentraciones de iones de sodio y cloro provocan un daño celular, lo que constituye un estrés iónico (Hasegawa 2013).

Para contrarrestar el aumento de la concentración de sodio citoplasmático, la célula posee dos mecanismos de detoxificación. El primero consiste en el eflujo de sodio citosólico hacia el apoplasto, mediado por anti transportadores sodio/protones de membrana plasmática $(\mathrm{Li}$ et al. 2008, Munns 2010). El segundo proceso se basa en el almacenamiento de sodio en la vacuola, mecanismo que también está mediado por anti transportadores sodio/protones (denominados proteínas NHX) los cuales secuestran sodio en la vacuola (Tuteja 2007).

Los genes $N H X$ vacuolares han sido caracterizados en diferentes especies vegetales de interés agrícola, tales como trigo, arroz, tomate y tabaco, confirmándose su participación en respuesta a estrés hídrico y salino. Por lo tanto, el estudio y caracterización de $N H X$ se torna fundamental en las estrategias de manipulación genética con el objetivo de conferir un aumento de la tolerancia a la salinidad y sequía en muchas especies vegetales de relevancia económica. Sin embargo, son muy escasos los estudios realizados en especies forestales, destacándose entre estos la caracterización molecular de $\mathrm{NHX}$ en Populus euphratica Olivier (Ye et al. 2009), la sobreexpresión del gen $N H X$ de E. globulus en la planta modelo Arabidopsis thaliana (L.) Heynh. (Baltierra et al. 2013) y un estudio sobre la evolución divergente de los diferentes miembros de la familia de genes NHX en Populus euphratica (Meng y Wu 2018).

La hipótesis de este estudio propone que la respuesta a estrés abiótico en $E$. grandis, a través de la expresión del gen $N H X 1$, es similar a lo descrito en especies herbáceas. Concomitantemente, los objetivos principales de este estudio consisten en aislar el primer anti transportador sodio/ protones vacuolar descrito en esta especie (EgrNHX1), para posteriormente establecer su perfil de expresión tanto en tejido aéreo y en raíz bajo condiciones de estrés salino e hídrico, como también bajo el efecto de la fitohormona ácido abscísico. Para esto se determinan en este estudio las condiciones de salinidad y osmolaridad que inducen estrés abiótico en plantas jóvenes de E. grandis.

\section{MÉTODOS}

Análisis de la secuencia. La secuencia del gen codificante de la proteína vacuolar anti transportadora sodio /protones (EgrNHX1), se obtuvo utilizando como molde la secuencia, anotada en GeneBank, codificante para el gen NHXI de E. globulus (Baltierra et al. 2013), en la base de datos de EUCAGEN. ORG, la cual contiene el genoma de E. grandis.

El análisis de la secuencia se realizó utilizando las herramientas bioinformáticas que están disponibles en la base de datos NCBI (Altschul et al. 1997) y el árbol filogenético de la proteína se construyó con el programa MEGA 5.0 (Tamura et al. 2007) con 5.000 réplicas usando el algoritmo de Neighbor-Joining. Para este estudio se utilizaron solo secuencias de proteínas $N H X$ que hayan sido publicadas anteriormente: PeNHX5 (ACU01856), InNHX2 (BAD91200), OsNHX1 (BAA83337), GhNHX1(AAM54141), RhNHX (BAD93487), AgNHX1(BAB11940), HvNHX1(BAC56698), PeNHX2 (ACU01853), PeNHX3 (ACU01854), ZmNHX2 (ACG43655), HvNHX2 (AAO91943), ZmNHX4 (NP001105943), GmNHX1 (AAY43006), MdNHX1 (ADB92598), AthNHX6 (AAM08407), AthNHX5 (AAM08406), AthNHX4 (AAM08405), AthNHX2 (AAM08403), AthNHX1 
(Q68KI4), AthNHX3 (Q84WG1), AthNHX7 (Q9LKW9), AthNHX8 (AAZ76246) KcNHX2 (DQ3490).

Material vegetal y condiciones de crecimiento. Las semillas de $E$. grandis se germinaron en tierra, transfiriéndose posteriormente plantas jóvenes de cuatro meses de vida a un sistema de crecimiento en medio hidropónico con $0,4 \mathrm{~g}$ $\mathrm{L}^{-1}$ de sustrato Phostrogen (Home \& garden Ltd). Todas las plantas en sus diferentes etapas de crecimiento se mantuvieron en condiciones de invernadero con un fotoperiodo de 16 horas luz/ 8 horas oscuridad a una temperatura promedio de $21{ }^{\circ} \mathrm{C}$.

Para evaluar la fuga electrolítica, las plantas en cultivo hidropónico se sometieron a condiciones de estrés salino $(75,100$ y $150 \mathrm{mM}$ de cloruro de sodio durante 0,12 y 24 horas) y a condiciones de estrés hídrico, el cual fue provocado utilizando dos estrategias: Polietilenglicol 6.000 al $10 \%$ durante $0,10,20$ y 30 horas o $300 \mathrm{mM}$ Manitol durante los mismos intervalos de tiempo.

La expresión del gen EgrNHX1 se cuantifico a través de PCR en tiempo real, a partir de ARN extraído de plántulas de $E$. grandis en cultivo hidropónico, las cuales se sometieron a diferentes tratamientos con $100 \mu \mathrm{M}$ de ácido abscísico (ABA), $100 \mathrm{mM}$ de cloruro de sodio y $300 \mathrm{mM}$ de manitol durante $0,0,5,1,0,1,5,2,3,4,6,8,12,16,20$ y 24 horas.

Medición de fuga electrolítica o permeabilidad de membrana. Con el fin de determinar las condiciones de salinidad y el mejor modelo de estrés osmótico para inducir estrés salino e hídrico respectivamente, se realizó un ensayo de fuga electrolítica. La fuga se midió en hojas provenientes de $E$. grandis de cuatro meses de vida utilizando el protocolo descrito por Rizhsky et al. (2002). Se realizaron dos réplicas independientes con discos de hojas provenientes de 10 plantas distintas en cada medición.

Extracción de RNA y PCR en tiempo real. La extracción de ARN total se realizó a partir de hojas o raíces de plantas de E. grandis de cuatro meses de vida utilizando como agente reductor polivinilpirrolidona y $\beta$-mercaptoetanol, con una extracción final con cloroformo para remover restos de proteínas y en la re-suspensión final $\mathrm{NaCl}$ para remover restos de polisacáridos, según el protocolo descrito por Chang et al. (1993). Se realizaron tres extracciones independientes para cada población sometida a estrés salino, hídrico y al tratamiento con $\mathrm{ABA}$, respectivamente.

Para la síntesis de ADNc se utilizó 250 ng de ARN tratado previamente con DNAsa I. La retrotranscripción se realizó utilizando el sistema Super Script II First-Strand Synthesis (Invitrogen) siguiendo las instrucciones del fabricante. El PCR se realizó utilizando Eva Green QPCR Master Mix con 40 ciclos de amplificación $\left(95^{\circ} \mathrm{C}\right.$ por $10 \mathrm{~s}$, seguido por $64{ }^{\circ} \mathrm{C}$ por $15 \mathrm{~s} \mathrm{y} 72^{\circ} \mathrm{C}$ por $20 \mathrm{~s}$ ). Para el análisis de expresión por PCR tiempo real se utilizó el método de expresión corregido por eficiencia descrito por Pfaffl (Pfaffl 2001), el cual se basa en la cuantificación de tran- scritos en comparación con una curva de calibración de un gen de referencia con una eficiencia de expresión máxima y conocida. Se utilizaron partidores específicos para el gen EgrNHX1 (qEgrNHX1 F 5'-TGTTGGGATTGGGCTCAGGA-3' y qEgrNHX1 R 5'-TGACAGTGCCAAACACTCCA -3') y como gen constitutivo de la expresión se utilizó histona H4 (qEgrH4 F 5'-GAAGCGGCACAGAAAGGTC-3' y qEgrH4 R 5'-GCGTCGCGGATCACGTT-3'). Para cada ADNc de E. grandis se realizaron tres reacciones de PCR en tiempo real, analizándose estadísticamente los datos con el programa Graph Pad Prism 5.

Análisis estadístico. Todos los experimentos se realizaron con tres replicas para cada tratamiento. Los datos fueron analizados estadísticamente utilizando Microsoft Excel 2013 para estimar promedio y error standard error, y el programa SPSS19.0 para realizar ANDEVA y la prueba de Tukey con una probabilidad de 0,05 .

\section{RESULTADOS}

Aislamiento y análisis bioinformático de la secuencia. Como resultado del análisis BLAST se obtuvo una secuencia genómica formada por 4.723 pares de bases y 14 exones, los cuales conforman un putativo ADNc de 1.626 pares de bases. Esta secuencia presenta un $99 \%$ de identidad nucleotídica con la secuencia de $N H X 1$ de E. globulus (EgNHX1).

La traducción in silico del ADNc de EgrNHX1 reveló una proteína putativa de 541 aminoácidos, definida como un intercambiador sodio protones mediante un análisis de semejanza en InterPro Scan, presentando los cuatro dominios característicos para las familias de intercambiadores sodio/protones. Además, se determinó la relación filogenética de esta proteína con respecto a otras proteínas $N H X$ reportadas en la literatura (figura 1), observándose que EgrNHX1 agrupa junto con EgNHX1 (E. globulus) y PeNHX5 (P. euphratica), ambas proteínas transportadoras $N H X$ vacuolares provenientes de especies leñosas.

Fuga electrolítica. En primer lugar, se trataron las plantas con concentraciones crecientes de cloruro de sodio (desde 0 hasta $150 \mathrm{mM}$ ), determinándose los porcentajes de fuga electrolítica a las 0,12 y 24 horas. En los tratamientos con las concentraciones de 75 y $100 \mathrm{mM}$ de cloruro de sodio, el porcentaje de fuga obtenido no mostró diferencias significativas con respecto al control sin tratamiento. Sin embargo, las plantas sometidas a $150 \mathrm{mM}$ exhibieron un alto porcentaje de fuga electrolítica desde las 12 horas, sugiriendo que esta concentración de sal produce un estrés significativo en las plantas de $E$. grandis ocasionando un daño celular que es posible de medir (figura 2A).

Por otro lado, la aplicación de polietilenglicol no provocó una variación significativa en relación al control sin tratamiento, mientras que la aplicación de manitol genera un alto nivel de fuga electrolítica desde las primeras horas 


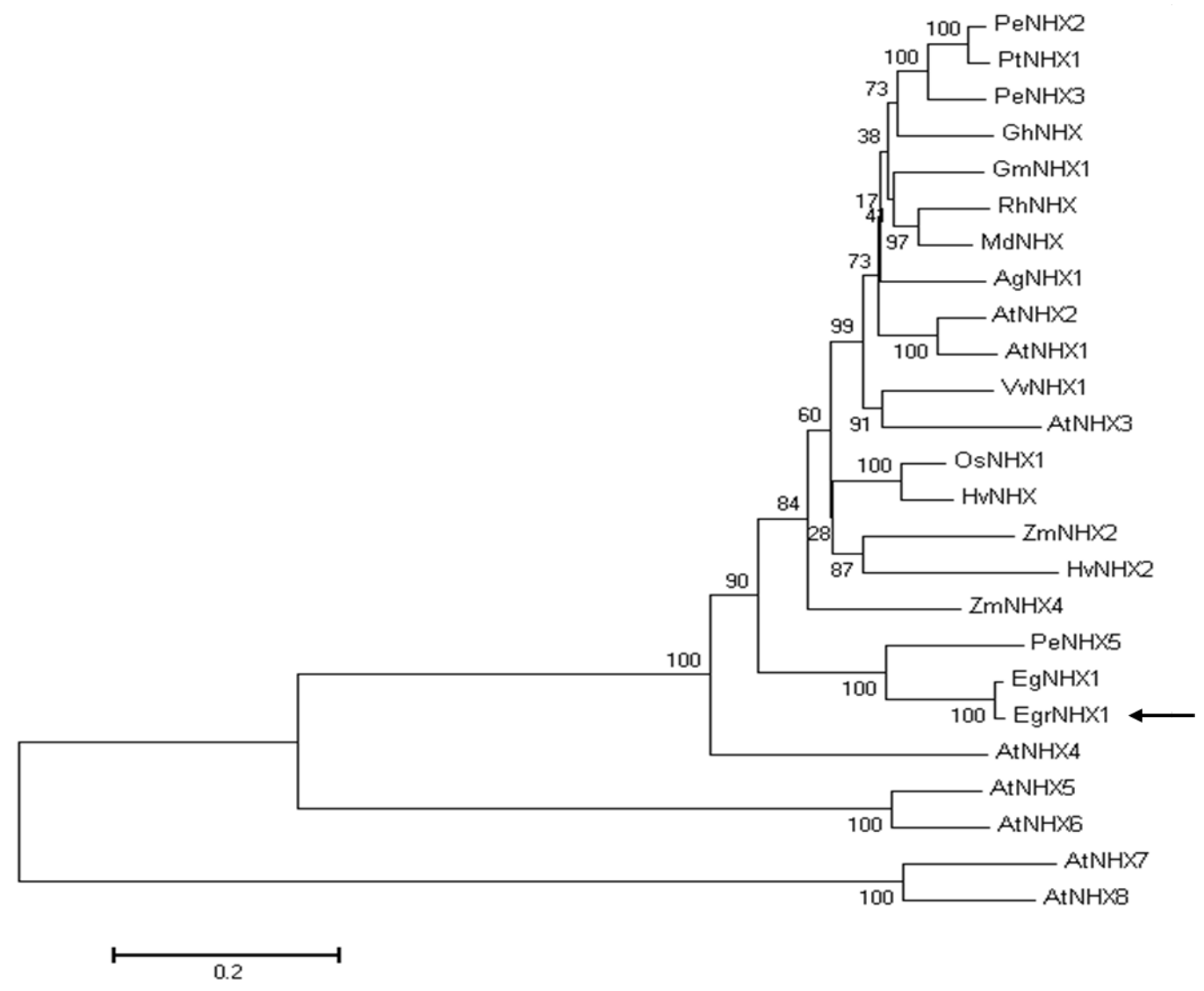

Figura 1. Árbol filogenético de proteínas NHX. Los valores de confianza están indicados en cada rama de divergencia, la secuencia correspondiente a E. grandis está indicada con una flecha negra. Eg: E. globulus; Egr: E. grandis At: A. thaliana. Pe: P. euphratica; Pt: Populus tormentosa; Os: Oryza sativa; Gh: Gossypium hirsutum; Rh: Rosa hybrid; Gm: Glycine max; Md: Malus domestica; Ag: Atriplex gmelinii; Vv: Vitis vinifera; Zm: Zea mays; Hv: Hordeum vulgare.

Phylogenetic tree of NHX proteins. The confidence values are indicated in each branch of divergence, the sequence corresponding to E. grandis is indicated with a black arrow.

de tratamiento ocasionando un daño cuantificable en las membranas de E. grandis (figura 2B).

Al comparar la respuesta a la exposición a manitol (estrés osmótico) con la respuesta a la exposición a $\mathrm{NaCl}$ (condición salina), se observó que ambas curvas presentaron el mismo comportamiento aumentando significativamente durante las primeras horas de tratamiento y un incremento menor en los tiempos finales.

Estudio de expresión del gen EgrNHX1. A partir de los resultados obtenidos en los ensayos de fuga electrolítica, se definió como condición de estrés la aplicación de $150 \mathrm{mM}$ de cloruro de sodio para estrés salino y $300 \mathrm{mM}$ de manitol para estrés osmótico. Además, se estudió la expresión de EgrNHX1 bajo la acción de la fitohormona de respuesta a estrés ácido abscísico $100 \mu \mathrm{M}$.

$\mathrm{Al}$ aplicar cloruro de sodio $150 \mathrm{mM}$ se observó un leve aumento de la expresión en hojas a partir de las 4 horas de tratamiento, aumentando significativamente después de las 16 horas, y alcanzando un máximo en la acumulación de transcrito a las 24 horas de tratamiento (figura 3). De la misma forma la acumulación de transcrito de $\operatorname{EgrNHX1}$ en raíz comienza después de las 8 horas de tratamiento, con un máximo de expresión a las 20 horas (figura 3).

$\mathrm{Al}$ analizar el perfil de expresión de las plantas tratadas con manitol, se observó un aumento leve de la expresión en hojas a partir de las cuatro horas de tratamiento, alcanzando un máximo de expresión a las 16 horas. En los tiempos posteriores se visualizó una disminución en la expresión de EgrNHX1, aun cuando esta fue significativamente mayor a la establecida para el tiempo cero (figura 4). En las raíces de plantas tratadas con manitol se observó un aumento de la expresión en los primeros 30 minutos, fluctuando posteriormente la expresión hasta las primeras seis horas de tratamiento. Transcurridas 8 horas de tratamiento ocurre un aumento significativo de la expresión de EgrNHX1, promediando 6,5 veces de cambio entre las 8 y 24 horas (figura 4).

Dado que el ácido abscísico actúa como molécula señalizadora que activa la expresión de genes de respuesta a estrés salino y osmótico (Tuteja 2007), se estudió el nivel 
de expresión de EgrNHX1 en plantas de E. grandis tratadas con $100 \mu \mathrm{M}$ de ABA exógeno por distintos periodos de tiempo.

Se observó que en los tratamientos con ABA exógeno ocurre un aumento de la expresión de EgrNHXI en dos periodos de tiempo en el tejido aéreo. El primer aumen- to detectado es leve y estadísticamente no significativo, transcurriendo desde la primera hora de exposición hasta las seis horas (figura 5). Luego ocurre un segundo aumento de la acumulación de transcrito de $\operatorname{EgrNHX1}$, el cual es significativo desde las 16 horas de tratamiento, alcanzando un máximo a las 24 horas.
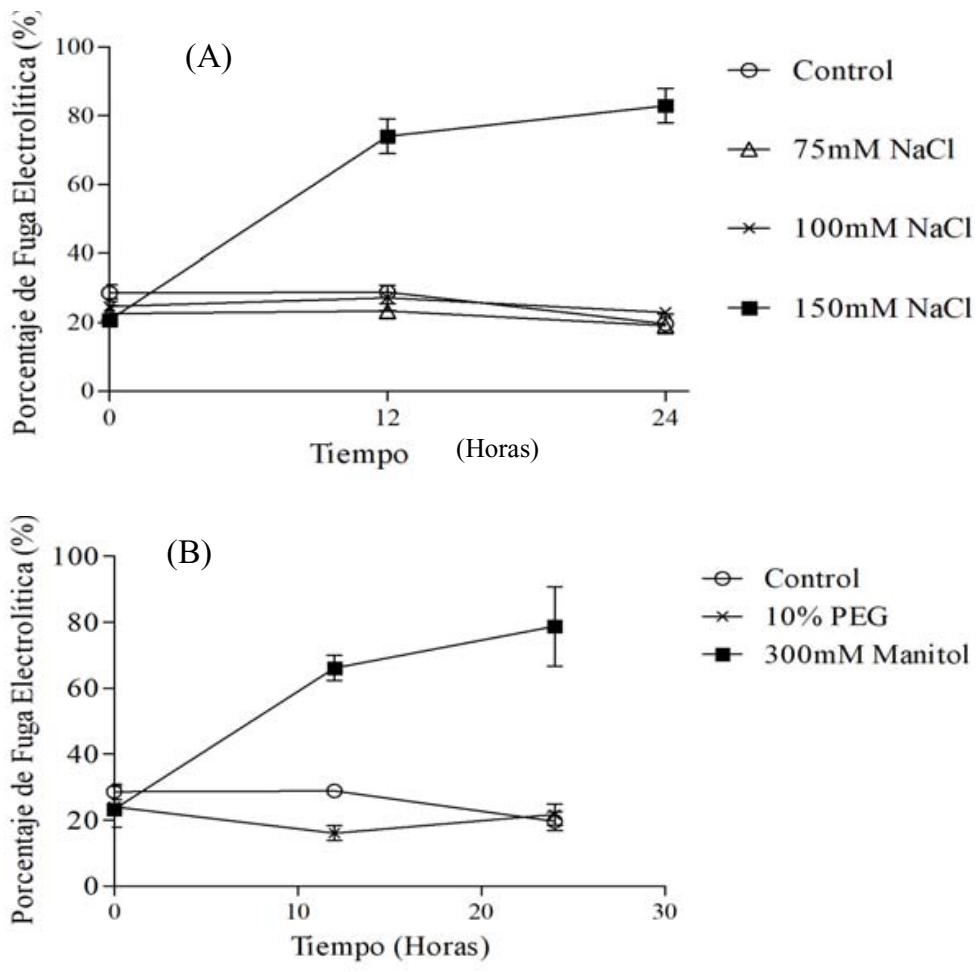

Figura 2. Porcentaje de fuga electrolítica en plantas de E. grandis sometidas a estrés: A) salino, B) osmótico.

Electrolyte leakage measurements of E. grandis subjected to: A) salt stress and B) drought stress.
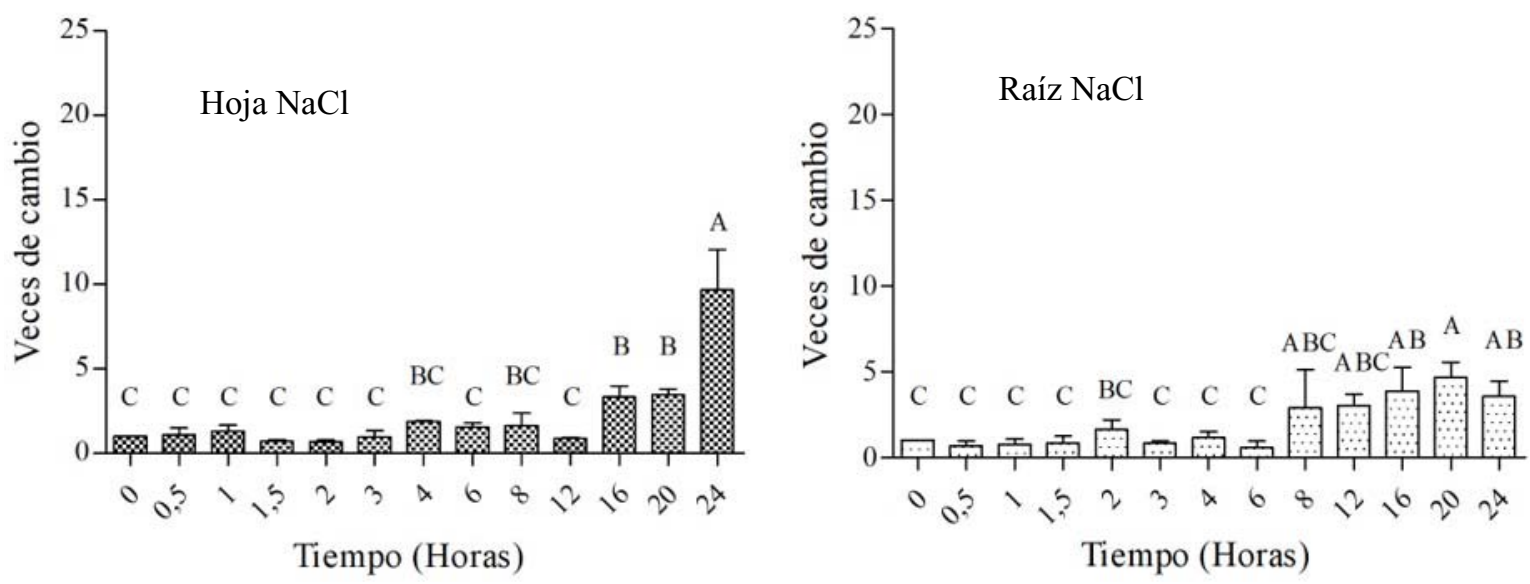

Figura 3. Análisis de expresión de transcritos de $\operatorname{Egr} N H X 1$ en respuesta a estrés salino ( $150 \mathrm{mM}$ de cloruro de sodio), mediante PCR en tiempo real. En cada gráfico las columnas no conectadas por la misma letra son significativamente distintas entre sí $(P<0,05)$.

Analysis of transcript expression of $E g r N H X 1$ in response to salt stress (150 mM de sodium chloride) through real time PCR. In each graph the columns not connected by the same letter are significantly different from each other $(P<0.05)$. 
Por el contrario, en raíces de plantas de E. grandis tratadas con ABA exógeno durante las cuatro primeras horas de tratamiento los niveles de transcrito no se vieron modificados en relación con el tiempo 0 (figura 5). A partir de seis horas de exposición se observó un fuerte aumento de la expresión de EgrNHXI, alcanzando un máximo de 34 veces de cambio luego de 20 horas de tratamiento, para posteriormente disminuir nuevamente a las 24 horas de tratamiento.

\section{DISCUSIÓN}

De acuerdo con los resultados obtenidos a partir del análisis filogenético, se puede decir que la secuencia aislada desde E. grandis correspondería al gen ortólogo del intercambiador vacuolar NHX1 descrito por Baltierra et al. (2013) en E. globulus. Asimismo, del análisis comparativo de los niveles de expresión en tejido aéreo de EgrNHXI en condiciones de estrés salino y osmótico se desprende que los perfiles de expresión son muy similares sin presentar cambios significativos durante las tres primeras horas obteniéndose los mayores valores de expresión a partir de las 16 horas de tratamiento. Esto sugiere que bajo estas condiciones de evaluación el componente osmótico del estrés salino es el que tendría mayor relevancia, no siendo capaces de visualizar la fase iónica del estrés salino, la cual se presentaría posteriormente cuando el nivel de sodio citoplasmático alcance niveles tóxicos para la célula lo que puede tardar varias horas incluso días en aparecer (Munns
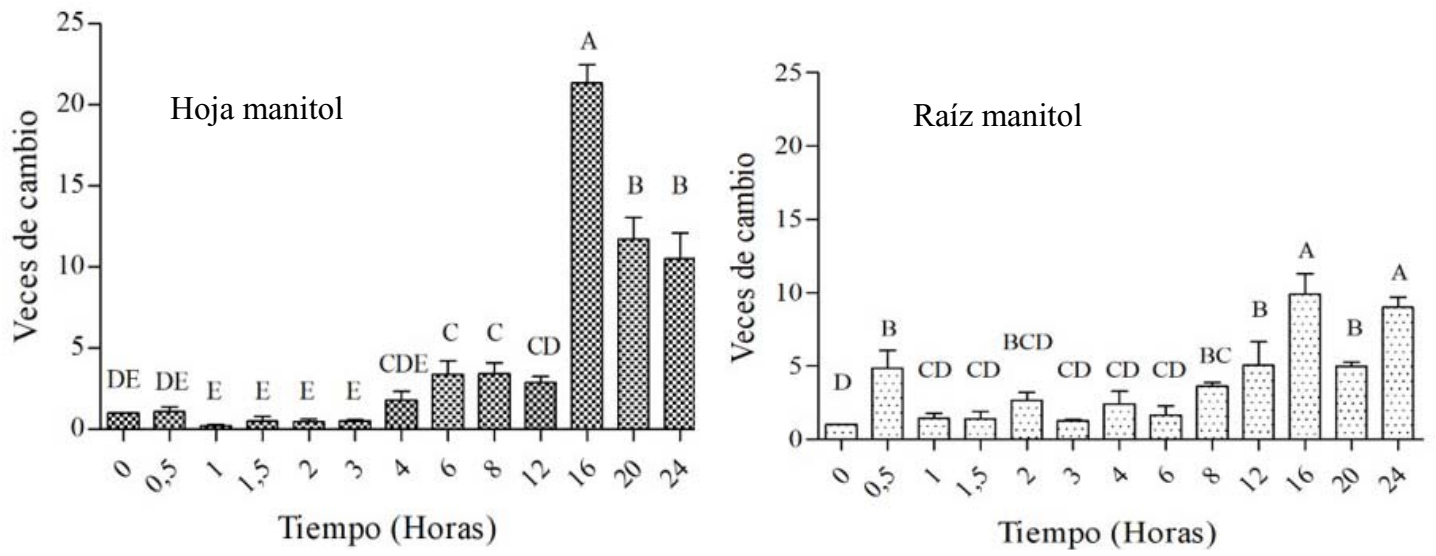

Tiempo (Horas)

Figura 4. Análisis de expresión de transcritos de $E g r N H X 1$ en respuesta a estrés osmótico manitol 300 mM, mediante PCR en tiempo real. En cada gráfico las columnas no conectadas por la misma letra son significativamente distintas entre sí $(P<0,05)$.

Analysis of transcript expression of EgrNHX1 in response to osmotic stress (manitol $300 \mathrm{mM}$ ) through real time PCR. In each graph the columns not connected by the same letter are significantly different from each other $(P<0.05)$.

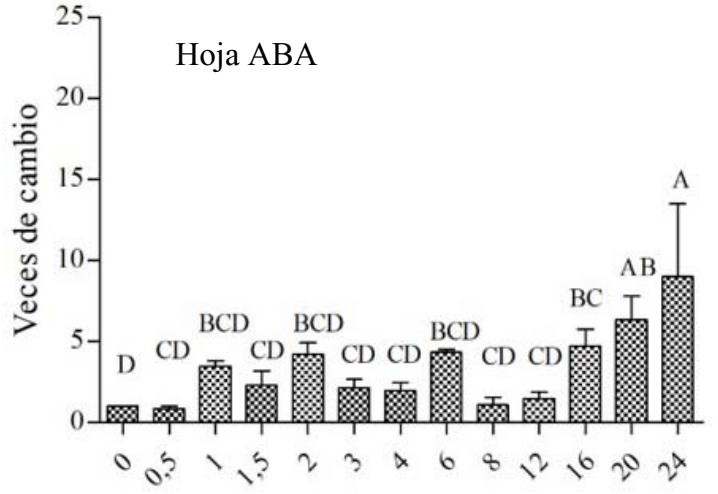

Tiempo (Horas)

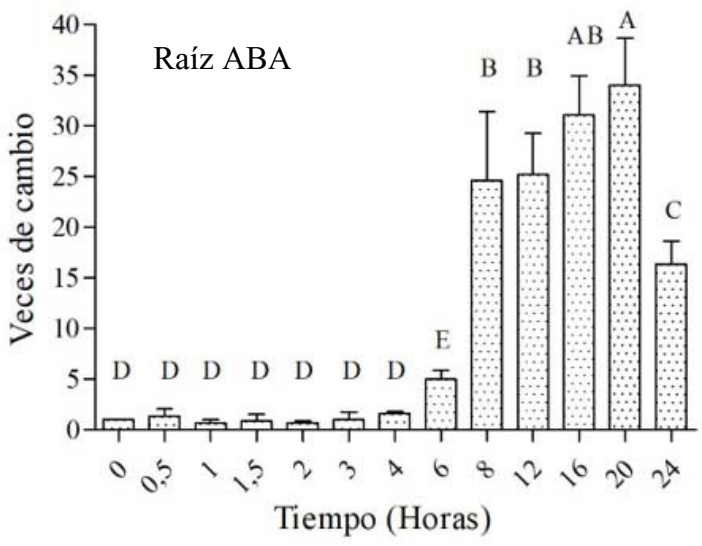

Figura 5. Análisis de expresión de transcritos de $\operatorname{EgrNHX1}$ en respuesta fitohormona ácido abscísico (100 $\mu \mathrm{M})$, mediante PCR en tiempo real. En cada gráfico las columnas no conectadas por la misma letra son significativamente distintas entre sí $(P<0,05)$.

Analysis of transcript expression of EgrNHX1 in response to abscisic acid phytohormone $(100 \mu \mathrm{M})$ through real time PCR. In each graph the columns not connected by the same letter are significantly different from each other $(P<0.05)$. 
2010). Por otro lado, el análisis de la expresión bajo la acción de la fitohormona ABA demuestra un aumento de la expresión previo a lo observado en los tratamientos de estrés salino y osmótico, lo que sugiere que la respuesta al estrés del gen $N H X 1$ en E. grandis es dependiente de $\mathrm{ABA}$, tal como fue reportado anteriormente para el gen NHX1 de álamo (Populus trichocarpa Torr. et Gray.) (Tian et al. 2017). La expresión de transcritos en la raíz bajo estrés salino y exposición a $\mathrm{ABA}$, presentan cinéticas de acumulación de transcrito similares, mientras que el perfil de expresión bajo condiciones de estrés osmótico difiere presentando una acumulación más temprana en los primeros 30 minutos de tratamiento. Estos resultados sugieren que en las primeras horas del estrés osmótico ocurre una regulación del gen EgrNHX1 independiente de ABA, lo que daría cuenta de una regulación conjunta de este gen a través de vías dependientes e independientes de esta hormona (Zhang et al. 2016).

A base de los patrones de expresión de EgrNHX1 y los antecedentes anteriormente publicados (Baltierra et al. 2013), se sugiere que la expresión de este gen está regulada frente a estrés salino como a estrés osmótico, siendo su función en la fase temprana del estrés salino secuestrar iones sodio en la vacuola permitiendo de esta forma el ajuste osmótico de la célula frente a estrés salino. ABA participaría en la regulación diferencialmente en hoja y en raíz, siendo tempranamente activada en hojas y más tardíamente, pero en niveles mayores en raíz.

La regulación temprana por $\mathrm{ABA}$ en hoja podría deberse a la liberación de ABA desde reservorios en las vacuolas de las hojas o a la síntesis de novo en este tejido, lo que induciría una respuesta rápida pero transitoria frente a estrés osmótico, activando factores de transcripción que dependen de ABA para ejercer su acción en los promotores de genes de respuesta a estrés (Agarwal y Jha 2010). Por el contrario, en raíz, la activación de genes de respuesta a estrés sería tardía pero fuerte y mantenida en el tiempo ya que en este tejido se sintetizaría $\mathrm{ABA}$ de novo redistribuyéndose en la planta y activando fuertemente los genes de respuesta a estrés, permitiendo la compartamentalización de sodio en la vacuola, tanto en la primera fase de ajuste osmótico como la fase más tardía de toxicidad iónica (Umezawa et al. 2010, Seo y Koshiba 2011).

\section{CONCLUSIONES}

En este estudio se determinó que la expresión de $N H X 1$ aumenta tanto en tejido aéreo como en raíz en una respuesta dependiente de la hormona ácido abscísico, confirmándose la hipótesis que la respuesta a estrés abiótico en esta especie, a través de la expresión del gen $N H X 1$, es similar a lo descrito en especies herbáceas.

Con todo lo anterior, este gen se confirma como un potencial candidato para programas de mejoramiento genético en especies leñosas con el fin de seleccionar individuos capaces de combatir la desertificación.

\section{AGRADECIMIENTOS}

Proyecto Financiamiento Basal (AFB170004).

\section{REFERENCIAS}

Agarwal PK, B Jha. 2010. Transcription factors in plants and ABA dependent and independent abiotic stress signaling. Biologia Plantarum 54(2): 201-212. DOI: $10.1007 /$ s10535-010-0038-7.

Altschul S, T Madden, A Schaffer, J Zhang, Z Zhang, W Miller, D Lipman. 1997. Gapped BLAST and PSI-BLAST: a new generation of protein database search programs. Nucleic Acids Research 25: 3389-3402. DOI: 10.1093/nar/25.17.3389.

Baltierra F, M Castillo, MC Gamboa, M Rothhammer, E Krauskopf. 2013. Molecular characterization of a novel $\mathrm{Na}+\mathrm{H}+$ antiporter cDNA from Eucalyptus globulus. Biochemical and Biophysical Research Communications 430(2):535540. DOI: 10.1016/j.bbrc.2012.11.118

Casanova M, O Salazar, O Seguel, W Luzio. 2013. The soils of Chile. Dordrecht, The Netherlands. Springer. p. 99-119.

Chang S, J Puryear, J Cairney. 1993. A simple and efficient method for isolating RNA from pines trees. Plant Molecular Biology 11: 113-116. DOI: 10.1007/BF02670468.

Fuenzalida H, P Aceituno, M Falvey, R Garreaud, M Rojas, R Sanchez. 2006. Estudio de la variabilidad climática en Chile para el siglo XXI. Informe final. Santiago, Chile. CONAMA, Ministerio del Medio Ambiente. 63 p. http://dgf.uchile.cl/ PRECIS/articles-39442 pdf Estudio texto.pdf

Goodstein DM, S Shu, R Howson, R Neupane, RD Hayes, J Fazo, T Mitros, W Dirks, U Hellsten, N Putnam, DS Rokhsar. 2012. Phytozome: A comparative platform for green plant genomics. Nucleic Acids Research 40(D1): D1178D1186. DOI: $10.1093 /$ nar/gkr944.

Hasegawa PM. 2013. Sodium $(\mathrm{Na}+)$ homeostasis and salt tolerance of plants. Environmental and Experimental Botany 92(0):19-31. DOI: 10.1016/j.envexpbot.2013.03.001.

INFOR (Instituto Forestal, CL). 2016. Anuario Forestal 2016. Santiago, Chile. INFOR. 171 p. https://wef.infor.cl/publicaciones/anuario/2016/Anuario2016.pdf

Jamil A, S Riaz, M Ashraf, MR Foolad. 2011. Gene expression profiling of plants under salt stress. Critical Reviews in Plant Sciences 30(5): 435-458. DOI: 10.1080/07352689.2011.605739.

Li JY, XW He, L Xu, J Zhou, P Wu, HX Shou, FC Zhang. 2008. Molecular and functional comparisons of the vacuolar $\mathrm{Na}+/ \mathrm{H}+$ exchangers originated from glycophytic and halophytic species. Journal of Zhejiang University SCIENCE B 9(2):132-140. DOI: 10.1631/jzus.B0710445.

Lu S, L Li, X Yi, CP Joshi, VL Chiang. 2008. Differential expression of three eucalyptus secondary cell wall-related cellulose synthase genes in response to tension stress. Journal of Experimental Botany 59(3): 681-695. DOI: $\underline{10.1093 / \mathrm{jxb} /}$ erm350.

Meng K, Y Wu. 2018. Footprints of divergent evolution in two $\mathrm{Na}+/ \mathrm{H}+$ type antiporter gene families (NHX and SOS1) in the genus Populus. Tree Physiology 38(6): 813-824. DOI: https://doi.org/10.1093/treephys/tpx173

Munns R. 2010. Approaches to identifying genes for salinity tolerance and the importance of timescale. Plant Stress Tolerance 639: 25-38. DOI: 10.1007/978-1-60761-702-0_2. 
Pfaffl MW. 2001. A new mathematical model for relative quantification in real-time RT PCR. Nucleic Acids Research 29(9): e45. DOI: $10.1093 / \mathrm{nar} / 29.9 . \mathrm{e} 45$

Rizhsky L, Liang H, Mittler R. 2002. The combined effect of drought stress and heat shock on gene expression in tobacco. Plant Physiology (130): 1143-1151. DOI: 10.1104/ pp.006858.

Seo M, T Koshiba. 2011. Transport of ABA from the site of biosynthesis to the site of action. Journal of Plant Research 124(4): 501-507. DOI: 10.1007/s10265-011-0411-4.

Tamura K, J Dudley, M Nei, S Kumar. 2007. MEGA4: Molecular Evolutionary Genetics Analysis (MEGA) software version 4.0. Molecular Biology and Evolution 24(8):1596-9. DOI: $10.1093 / \mathrm{molbev} / \mathrm{msm} 092$.

Tian F, Chang E, Li Y, Sun P, Hu J, Zhang J. 2017. Expression and integrated network analyses revealed functional divergence of NHX-type $\mathrm{Na}+/ \mathrm{H}+$ exchanger genes in poplar. Scientific Reports 7: 2607. DOI: 10.1038/s41598-017-02894-8.

Torres A, E Acevedo. 2008. El problema de salinidad en los recursos suelo y agua que afectan el riego y cultivos en los valles de Lluta y Azapa en el norte de Chile. Idesia (Arica) 26(3): 31-44. DOI: 10.4067/S0718-34292008000300004.

Tuteja N. 2007. Mechanisms of high salinity tolerance in plants.
Methods in Enzymology 428: 419-438. DOI: 10.1016/ S0076-6879(07)28024-3.

Umezawa T, K Nakashima, T Miyakawa, T Kuromori, M Tanokura, K Shinozaki, K Yamaguchi-Shinozaki. 2010. Molecular basis of the core regulatory network in ABA responses: sensing, signaling and transport. Plant and Cell Physiology 51(11):1821-1839. DOI: $10.1093 / \mathrm{pcp} / \mathrm{pcq} 156$.

Westphal C, P Gachon, J Bravo, C Navarrete, C Salas, C Ibanez. The Potential of Algarrobo (Prosopis chilensis (Mol.) Stuntz) for Regeneration of Desertified Soils: Assessing Seed Germination Under Saline Conditions. 2015. Environmental Management 56(1): 209-220. DOI: $10.1007 /$ s00267-015-0490-4.

Ye CY, HC Zhang, JH Chen, XL Xia, WL Yin. 2009. Molecular characterization of putative vacuolar NHX-type $\mathrm{Na}(+) / \mathrm{H}(+)$ exchanger genes from the salt-resistant tree Populus euphratica. Physiologia Plantarum 137(2):166174. DOI: 10.1111/j.1399-3054.2009.01269.x.

Zhang J, Y Haiyue, Y Zhang, Y Wang, M Li, J Zhang, L Duan, M Zhang, Z Li. 2016. Increased abscisic acid levels in transgenic maize overexpressing AtLOS5 mediated root ion fluxes and leaf water status under salt stress. Journal of Experimental Botany 67(5): 1339-1355. DOI: 10.1093/jxb/erv528 